\title{
Prevalence of impacted third molars in the South African Indian population of the eThekwini Metropolitan Region
}

\author{
SADJ July 2019, Vol. 74 No. 6 p302 - p309
}

S Ishwarkumar', P Pillay², MR Haffajee ${ }^{2}$, KS Satyapal ${ }^{2}$

\section{SUMMARY}

\section{Introduction}

An impacted tooth is partially erupted or un-erupted, positioned against another tooth, bone or soft tissue in such a way as to prevent further eruption. Normal dental arch relationships are disrupted.

This study investigated the prevalence of impactions of third molar teeth amongst Indians residing in the greater eThekwini Metropolitan area.

\section{Materials and methods}

A sample of 274 digital panoramic radiographs was examined. Impacted third molars were identified on 222 scans. The impactions were classified using Winter's, and Pell and Gregory's schemes. Statistical analysis was applied to determine any relationship between impactions and sex and age.

\section{Author affiliations:}

1. Sundika Ishwarkumar: B. Med Sci, H Med Sci, M Med Sci (UKZN), nGAP Lecturer, Department of Human Anatomy and Physiology, Faculty of Health Sciences, University of Johannesburg, Doornfontein Campus, Auckland Park, South Africa. ORCID Number: 0000-0002-3897-7015

2. Pamela Pillay: B. Med Sci, H Med Sci, M Med Sci cum laude, $P h D$ (UKZN), Senior Lecturer, Department of Clinical Anatomy, School of Laboratory Medicine and Medical Sciences, College of Health Sciences, University of KwaZulu-Natal, Westville Campus, South Africa.

ORCID Number: 0000-0001-5428-3016

3. Mohamed R Haffajee: MBBCh (Natal), Dip PEC (CMSA), FRCS (Edinburgh), ATLS (AEMS, Durban), FIACA, Retired Professor, Department of Clinical Anatomy, School of Laboratory Medicine and Medical Sciences, College of Health Sciences, University of KwaZulu-Natal, Westville Campus, Durban, South Africa.

4. Kapil S Satyapal: $L R C P, L R C S, L M$ (Royal College of Physicians \& Surgeons in Ireland); MD: General Surgery (Doctor of Medicine: University of Natal); FRCPI (Fellow of the Royal College of Physicians of Ireland); FICA (Fellow of the International College of Angiology, USA): Fellow of the University of Kwa-Zulu Natal; LLM (Medical Law) (UKZN), Emeritus Professor Department of Clinical Anatomy, College of Health Sciences, School of Laboratory Medicine and Medical Sciences, Westville Campus, College of Health Sciences, University of KwaZulu-Natal, Durban, South Africa. ORCID Number: 0000-0001-5239-2972

Corresponding author: Kapil S Satyapal

Department of Clinical Anatomy, College of Health Sciences, School of Laboratory Medicine and Medical Sciences, Westville Campus, College of Health Sciences, University of KwaZulu-Natal, Private Bag 54001, Durban, 4000. Tel: + 27 (0)31260 7899 Email: satyapalk@ukzn.ac.za

Author contributions:

1. Sundika Ishwarkumar: Data collection, statistical analysis and write-up of manuscript - $50 \%$

Pamela Pillay: Write-up of manuscript - $20 \%$

3. Mohamed R Haffajee: Write-up of manuscript - 10\%

4. Kapil S Satyapal: Write-up of manuscript - $20 \%$

\section{ACRONYMS}

DOH: Dental Therapy and Oral Hygiene Board

MDB: $\quad$ Medical \& Dental Board

OHPs: $\quad$ Oral Health Professionals

PCC: $\quad$ Professional Conduct Committee

\section{Results}

Eighty-one percent of individuals presented with at least one impacted third molar, mandibular frequency being significantly higher in both sexes $(p$-value $=0.000$ ). The most prevalent types of impaction were mesioangular (mandibular)and vertical angulation (maxillary).

For level of impaction, Class B and Class A were respectively most prevalent in the mandible and the maxilla. With the exception of angulation of impacted mandibular third molars on the right side, all parameters showed a statistically significant correlation with age ( $p$-value $=0.000)$.

\section{Conclusion}

The high frequency of these eruption problems in this study may alert maxillo-facial and dental surgeons, and forensic investigators, to potential clinical challenges.

\section{Keywords}

Mandible, maxilla, prevalence, third molar impaction, radiology.

\section{INTRODUCTION}

Tooth impaction is a pathological condition wherein a tooth is completely or partially unerupted and positioned against another tooth, bone or soft tissue, thus being prevented further eruption into its normal functioning position. ${ }^{1,2}$

The third molars, which are commonly called wisdom teeth, are the only teeth to erupt during adolescence or early adulthood, often referred to as the age of "wisdom," hence the name. ${ }^{1}$ However, variations exist in the age of eruption, which generally occurs between the ages of 18-24 years. ${ }^{3}$ The mandibular third molars are the most frequently impacted teeth in humans followed by the maxillary third molars, maxillary canines and mandibular canines. ${ }^{4}$ The factors causing third molar impaction include crowding, ectopic position of the tooth germs, supernumerary teeth, genetic factors and soft tissue or bony lesions. ${ }^{4,5}$ 
Many theories have been proposed to explain the prevalence of the impacted third molar and the majority discuss the relationship of jaw size to the tooth size. This is suggested to result from the regional differences in dietary habits. ${ }^{5}$

It has been recorded that as the mandibular third molar teeth are the last to erupt, they are therefore often impeded in their eruption and either become impacted or remain unerupted within the jaw bone. ${ }^{1}$

Impacted teeth are often associated with pericoronitis, incisor crowding, resorption of the adjacent tooth roots and temporo-mandibular joint dysfunction. ${ }^{1,2}$

Furthermore, the development of the third molar is used as a tool by many forensic dentists to assign age to young adults who have been victims of violent crimes, fires, motor vehicle and airplane accidents. ${ }^{6}$

This study aims to investigate the prevalence of impacted third molar teeth for the Indian population group presenting at public and private Health Dental Facilities that serve the greater eThekwini Metropolitan area.

\section{MATERIALS AND METHODS}

The third molar teeth were studied in 274 South Africans of Indian descent (129 males; 145 females) within an age range 16 to 30 years, as these are the dominant years for the occurrence of third molar impaction. The sample size was selected by convenience sampling.

The patients from the public sector were randomly selected from a public sector hospital which treats mainly Indian and Black patients. The private sector sample was randomly selected from four private practices from the eThekwini Region; which treat, in the main, patients of Indian origin. This study was a retrospective review that grouped the digital panoramic radiographs according to sex and age.

The ages were categorized into three intervals, viz. 16 19; 20 - 25 and 26 - 30 years, which was similar to the age intervals selected in previous studies. ${ }^{4,5}$

The methodology was devised to determine the prevalence of impactions among the greater eThekwini Metropolitan population, and to determine if impaction is related to age, sex, and side (right or left).

Radiographs were obtained from the Radiology Departments of one public sector hospital and from four private dental practices within the eThekwini region. All records were collected utilizing consecutive sampling and ranged from 2009-2015. Ethical Clearance was obtained (BE: 410/13).

\section{Inclusion criteria}

The inclusion criteria of this study were:

- Panoramic radiographs of patients between 16 and 30 years of age who presented with no history of trauma and whose records were complete.

\section{Exclusion criteria}

The exclusion criteria of this study were:

- Poor quality radiographs (distorted/blurred/unclear images as a result of technique and projection errors caused by patient preparation, viz. radiopaque artefacts and improper positioning of the patients).

- Panoramic radiographs of patients who presented with fracture of the jaws that may have affected the normal development of the permanent dentition.

- Panoramic radiographs of patients which showed an absence of a second molar tooth adjacent to the third molar.

\section{Morphological analysis}

The panoramic radiographs were examined by a single examiner (first author), using a Kodak digital x-ray viewer, to determine the prevalence and characteristics of the impacted third molars in the sample. The first author assessed the angles and the depth of impaction on two separate occasions to find intra-observer variability.

A second examiner (second author) assessed every $10^{\text {th }}$ digital panoramic radiographs using the same methodology to determine the inter-observer variability. The Student's $t$-test was then employed to compare the two sets of data. These characteristics included the angulations and level of the impacted third molars.

The classification schemes of the impacted mandibular and maxillary third molar teeth were as follows:

\section{- Angulation of impacted third molars}

The angulations of the impacted third molar were recorded using Winter's classification scheme. . $^{2,7}$

\section{- Level of impaction and relation to the ramus of the mandible}

The level of impaction was recorded using Pell and Gregory's classification scheme. ${ }^{9}$

\section{Statistical analysis}

An appropriate sample size was calculated by using the mathematical formulae $n=\frac{Z^{2} p q}{E^{2}}$ and the collected data were captured and analysed using the Statistical Package for Social Sciences (SPSS version 21.0) with the assistance of a biostatistician. The statistics used included the mean, range and standard derivation for each age interval. The Pearson Chi-Square Test, One-Way Anova Test and Independent Samples $t$-Test were used to analyse the relationship between age, sex and the prevalence of impaction. A 95\% confidence level was adhered to for all statistical tests. A $p$-value of less than 0.05 was considered to be statistically significant.

\section{RESULTS}

\section{Prevalence of impacted third molars}

Of the 274 panoramic radiographs, 222 (81.0\%) were found to show at least one impacted third molar with a male: female ratio of $1: 1.2$ (i.e. 101:121). A total of 709 impacted third molar teeth were identified among 
the 222 patients. The proportion of impacted mandibular third molars (56.4\%) was significantly higher than the impacted maxillary third molar $(43.6 \%)$ in both males and females ( $p$-value $=0.000)$ (Table 1; Figure 1). Impacted third molars were 0.3 times more prevalent in the mandible than in the maxilla, with a ratio of $1.3: 1.0$ $\left(\frac{400}{309}\right)$.
Both mandibular and maxillary third molar impactions were recorded to be more prevalent in females than males. Furthermore, the majority of the third molar impactions belonged to the age interval of 20-25 (39.2\%), followed by the 16-19 age interval (33.3\%) with the 26 -30 year interval being least prevalent (27.5\%).

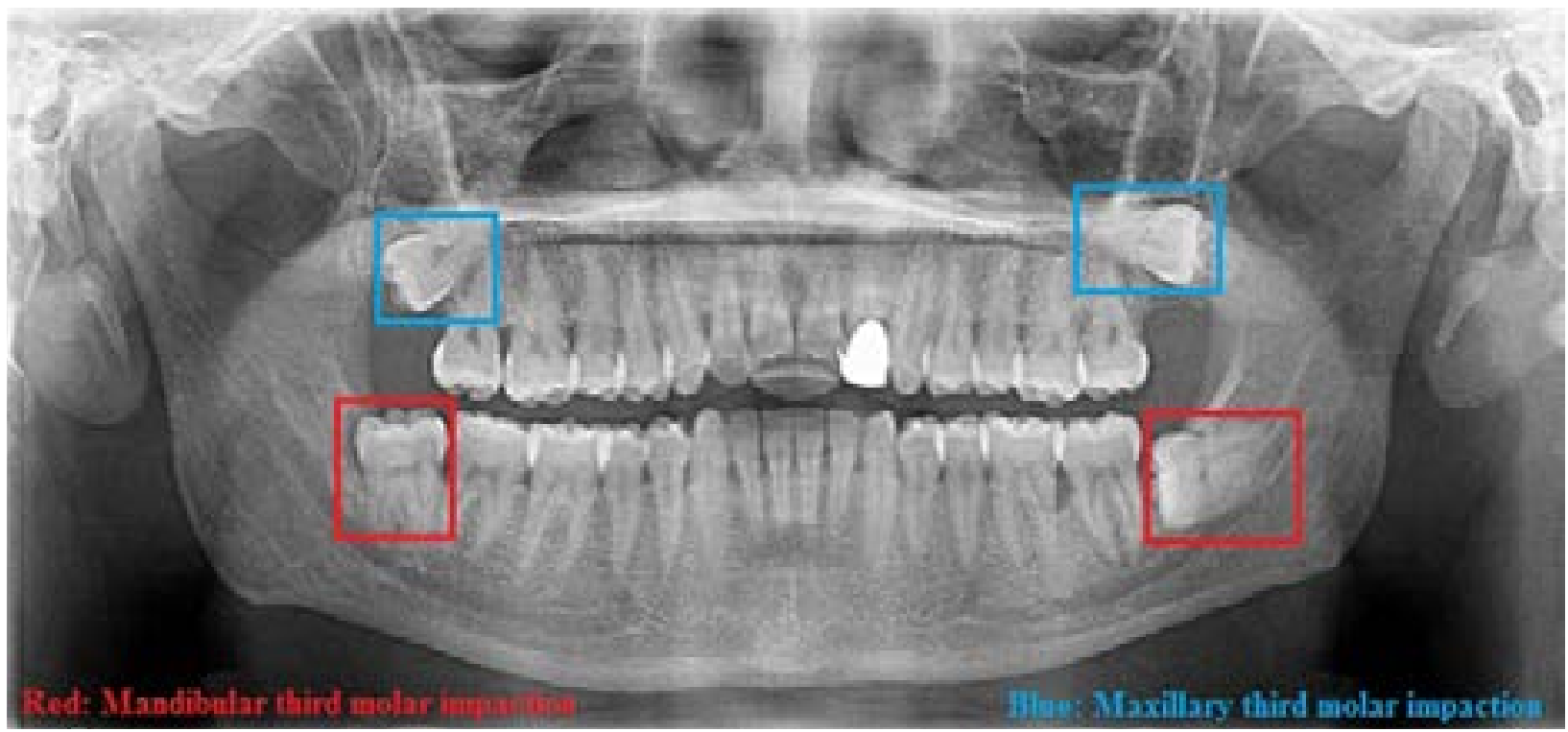

Figure 1. Impacted mandibular and maxillary third molars.

\begin{tabular}{|c|c|c|c|c|c|c|c|c|c|c|c|}
\hline \multirow{5}{*}{$\begin{array}{l}\text { Type of } \\
\text { Impaction }\end{array}$} & \multicolumn{11}{|c|}{ Prevalence (in \%) } \\
\hline & \multicolumn{11}{|c|}{ Mandible } \\
\hline & \multirow{2}{*}{\multicolumn{3}{|c|}{ Males }} & \multirow{2}{*}{\multicolumn{3}{|c|}{ Females }} & \multirow{2}{*}{ Both } & \multicolumn{4}{|c|}{$p$-value } \\
\hline & & & & & & & & \multicolumn{2}{|c|}{ Sex } & \multicolumn{2}{|c|}{ Age } \\
\hline & Right & Left & Total & Right & Left & Total & Total & Right & Left & Right & Left \\
\hline \multirow{2}{*}{$\begin{array}{c}\text { Mesio } \\
\text { angulation }\end{array}$} & 38 & 50 & 88 & 56 & 66 & 122 & 210 & \multirow{10}{*}{0.098} & \multirow{10}{*}{0.058} & \multirow{10}{*}{0.090} & \multirow{10}{*}{0.017} \\
\hline & (20.5) & $(27.0)$ & $(47.5)$ & $(26.0)$ & $(30.7)$ & $(56.7)$ & (52.5) & & & & \\
\hline \multirow{2}{*}{$\begin{array}{c}\text { Vertical } \\
\text { angulation }\end{array}$} & 23 & 20 & 43 & 31 & 22 & 53 & 96 & & & & \\
\hline & (12.4) & (10.8) & $(23.2)$ & $(14.4)$ & $(10.2)$ & $(24.6)$ & $(24.0)$ & & & & \\
\hline \multirow{2}{*}{$\begin{array}{l}\text { Horizontal } \\
\text { angulation }\end{array}$} & 29 & 25 & 54 & 18 & 16 & 34 & 88 & & & & \\
\hline & (15.7) & (13.5) & $(29.2)$ & (8.4) & (7.4) & (15.8) & $(22.0)$ & & & & \\
\hline \multirow{2}{*}{$\begin{array}{l}\text { Buccal } \\
\text { angulation }\end{array}$} & 0 & 0 & 0 & 0 & 0 & 0 & 0 & & & & \\
\hline & $(0.0)$ & $(0.0)$ & $(0.0)$ & $(0.0)$ & $(0.0)$ & $(0.0)$ & $(0.0)$ & & & & \\
\hline \multirow{2}{*}{$\begin{array}{c}\text { Disto } \\
\text { angulation }\end{array}$} & 0 & 0 & 0 & 2 & 4 & 6 & 6 & & & & \\
\hline & $(0.0)$ & $(0.0)$ & $(0.0)$ & $(0.9)$ & (1.9) & (2.8) & (1.5) & & & & \\
\hline \multirow{5}{*}{$\begin{array}{l}\text { Type of } \\
\text { Impaction }\end{array}$} & \multicolumn{11}{|c|}{ Prevalence (in \%) } \\
\hline & \multicolumn{11}{|c|}{ Maxilla } \\
\hline & \multirow{2}{*}{\multicolumn{3}{|c|}{ Males }} & \multirow{2}{*}{\multicolumn{3}{|c|}{ Females }} & \multirow{2}{*}{ Both } & \multicolumn{4}{|c|}{$p$-value } \\
\hline & & & & & & & & \multicolumn{2}{|c|}{ Sex } & \multicolumn{2}{|c|}{ Age } \\
\hline & Right & Left & Total & Right & Left & Total & Total & Right & Left & Right & Left \\
\hline \multirow{2}{*}{$\begin{array}{c}\text { Mesio } \\
\text { angulation }\end{array}$} & 5 & 2 & 7 & 7 & 4 & 11 & 18 & & & & \\
\hline & (3.7) & (1.5) & (5.2) & (4.0) & (2.3) & (6.3) & (5.8) & & & & \\
\hline Vertical & 49 & 44 & 93 & 51 & 62 & 113 & 206 & & & & \\
\hline angulation & (36.3) & (32.6) & (68.9) & (29.3) & (35.6) & (64.9) & (66.7) & & & & \\
\hline Horizontal & 0 & 2 & 2 & 0 & 0 & 0 & 2 & 0.196 & 0.458 & 0.000 & 0.000 \\
\hline angulation & $(0.0)$ & (1.5) & (1.5) & $(0.0)$ & $(0.0)$ & $(0.0)$ & (0.6) & 0.196 & 0.458 & 0.000 & 0.000 \\
\hline Buccal & 12 & 1 & 13 & 18 & 1 & 19 & 32 & & & & \\
\hline angulation & (8.9) & $(0.7)$ & (9.6) & (10.3) & $(0.6)$ & (10.9) & (10.4) & & & & \\
\hline Disto & 0 & 20 & 20 & 6 & 25 & 31 & 51 & & & & \\
\hline angulation & $(0.0)$ & (14.8) & (14.8) & (3.4) & (14.4) & (17.8) & (16.5) & & & & \\
\hline
\end{tabular}




\section{Angulation of impacted third molars}

\section{A. Impacted mandibular third molars}

The most common type of angulation for impacted mandibular third molars in both males and females was mesio-angulation $\left[\frac{210}{410}(52.5 \%)\right]$ (Figure 2), followed by vertical angulation $\left[\frac{96}{400}(24.0 \%)\right]$, with the least prevalent being disto-angulation $\left[\frac{6}{400}(2.8 \%)\right]$ (Table 1).

For the correlation with all age categories, only the type of mandibular angulation for the left side of the mandible was statistically significant with a $p$-value $=0.006$ (Table 1).

\section{B. Impacted maxillary third molars}

The most prevalent type of angulation for impacted maxillary third molars in both males and females was vertical $\left[\frac{206}{309}(66.7 \%)\right]$ (Figure 3), followed by distoangulation $\left[\frac{51}{309}(16.5 \%)\right]$, with the least prevalent being horizontal angulation $\left[\frac{2}{309}(0.6 \%)\right]$ (Table 1). A statistically significant relationship between the type of maxillary impaction and age was recorded $(p$-value $=0.000)$.

\section{Level of third molar impaction}

\section{A. Impacted mandibular third molars}

According to the Pell and Gregory classification scheme, ${ }^{9}$ Class B $\left[\frac{218}{400}(54.4 \%)\right]$ was recorded as the most prevalent type of mandibular third molar impaction, followed by Class C $\left[\frac{117}{400}(29.3 \%)\right]$, and the least prevalent, Class A [ $\left.\frac{65}{400}(16.3 \%)\right]$ (Table 2).

A statistically significant relationship was recorded between impacted mandibular third molars and age $(p$-value $=0.000)$.

\section{B. Impacted maxillary third molars}

While Class A [ $\frac{231}{309}$; $\left.(74.8 \%)\right]$ was recorded to be the most common type of maxillary third molar impaction, followed by Class C $\left[\frac{47}{309} ;(15.2 \%)\right]$ and Class B
[ $\left.\frac{31}{309} ;(10.0 \%)\right]$ (Table 2). A statistically significant relationship was recorded between this parameter and age $(p$-value $=0.000)$.

\section{Intra and Inter-observer variability}

The first author assessed all digital panoramic radiographs twice, yielding an intra examiner variability of 0.076 ( $p$-value $>0.05)$. A second author assessed every $10^{\text {th }}$ panoramic radiographs using the same classification.

No statistical significant difference between the two sets of data was recorded ( $p$-value $>0.05)$.

\section{DISCUSSION}

\section{Prevalence of impacted third molars}

Third molar impaction is a common problem affecting a large proportion of the world's population, with a global prevalence ranging from $16.7 \%$ to $68.6 \%{ }^{2}$ The current study estimated the prevalence of an impacted third molar among the South African Indian race group in the Greater eThekwini Metropolitan area of KwaZulu-Natal at $81.0 \%\left[\frac{222}{274}\right]$. This differs significantly when compared with a calculated weighted mean of $31.3 \%$ derived from a comparable series of studies which had investigated the prevalence of impacted third molars in different countries around the world (Table 3).

There are studies which do show similarities, however, for example, a $73.0 \%$ prevalence of impacted third molars was found among a young European population. ${ }^{10,11}$ Prevalences recorded in this study were higher than those previously reported (Table 3).,25,12,13 However, this study analysed radiographs of patients within a narrow age range (between 16-30 years) and the literature records that impacted third molars are most prevalent

\begin{tabular}{|c|c|c|c|c|c|c|c|c|c|c|c|}
\hline \multirow{5}{*}{$\begin{array}{l}\text { Level of } \\
\text { Impaction }\end{array}$} & \multicolumn{11}{|c|}{ Prevalence (in \%) } \\
\hline & \multicolumn{11}{|c|}{ Mandible } \\
\hline & \multirow{2}{*}{\multicolumn{3}{|c|}{ Males }} & \multirow{2}{*}{\multicolumn{3}{|c|}{ Females }} & \multirow{2}{*}{ Both } & \multicolumn{4}{|c|}{$p$-value } \\
\hline & & & & & & & & \multicolumn{2}{|c|}{ Sex } & \multicolumn{2}{|c|}{ Age } \\
\hline & Right & Left & Total & Right & Left & Total & Total & Right & Left & Right & Left \\
\hline \multirow{2}{*}{ A } & 12 & 18 & 30 & 19 & 16 & 35 & 65 & \multirow{6}{*}{0.801} & \multirow{6}{*}{0.512} & \multirow{6}{*}{0.000} & \multirow{6}{*}{0.000} \\
\hline & (6.5) & (9.7) & (16.2) & (8.8) & $(7.4)$ & (16.3) & (16.3) & & & & \\
\hline \multirow{2}{*}{ B } & 53 & 48 & 101 & 58 & 59 & 117 & 218 & & & & \\
\hline & (28.6) & (25.9) & $(54.6)$ & $(27.0)$ & $(27.4)$ & $(54.4)$ & (54.5) & & & & \\
\hline \multirow{2}{*}{$\mathrm{C}$} & 25 & 29 & 54 & 30 & 33 & 63 & 117 & & & & \\
\hline & (13.5) & (15.7) & (29.2) & $(14.0)$ & (15.3) & (29.3) & (29.2) & & & & \\
\hline \multirow{5}{*}{$\begin{array}{l}\text { Level of } \\
\text { Impaction }\end{array}$} & \multicolumn{11}{|c|}{ Prevalence (in \%) } \\
\hline & \multicolumn{11}{|c|}{ Maxilla } \\
\hline & \multirow{2}{*}{\multicolumn{3}{|c|}{ Males }} & \multirow{2}{*}{\multicolumn{3}{|c|}{ Females }} & \multirow{2}{*}{ Both } & \multicolumn{4}{|c|}{$p$-value } \\
\hline & & & & & & & & \multicolumn{2}{|c|}{ Sex } & \multicolumn{2}{|c|}{ Age } \\
\hline & Right & Left & Total & Right & Left & Total & Total & Right & Left & Right & Left \\
\hline \multirow{2}{*}{ A } & 49 & 52 & 101 & 60 & 70 & 130 & 231 & \multirow{6}{*}{0.893} & \multirow{6}{*}{0.619} & \multirow{6}{*}{0.000} & \multirow{6}{*}{0.000} \\
\hline & (36.3) & $(38.5)$ & $(74.8)$ & $(34.5)$ & $(40.2)$ & $(74.7)$ & (74.8) & & & & \\
\hline \multirow{2}{*}{ B } & 8 & 6 & 14 & 8 & 9 & 17 & 31 & & & & \\
\hline & (5.9) & $(4.4)$ & (10.3) & (4.6) & $(5.2)$ & (9.8) & $(10.0)$ & & & & \\
\hline \multirow{2}{*}{$\mathrm{C}$} & 9 & 11 & 20 & 14 & 13 & 27 & 47 & & & & \\
\hline & (6.7) & (8.1) & (14.8) & (8.0) & (7.5) & (15.5) & (15.2) & & & & \\
\hline
\end{tabular}




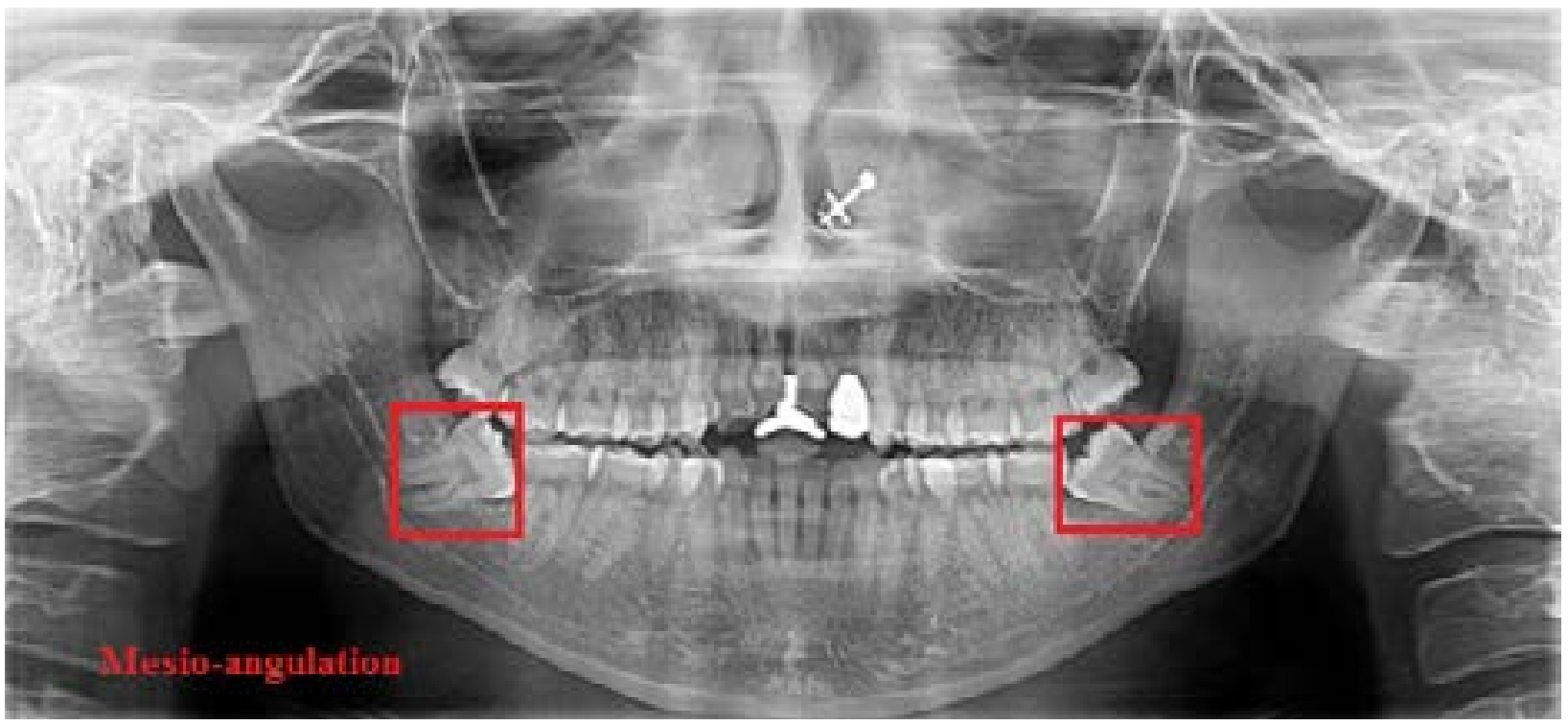

Figure 2. Mesio-angulation impaction of the mandibular third molars.

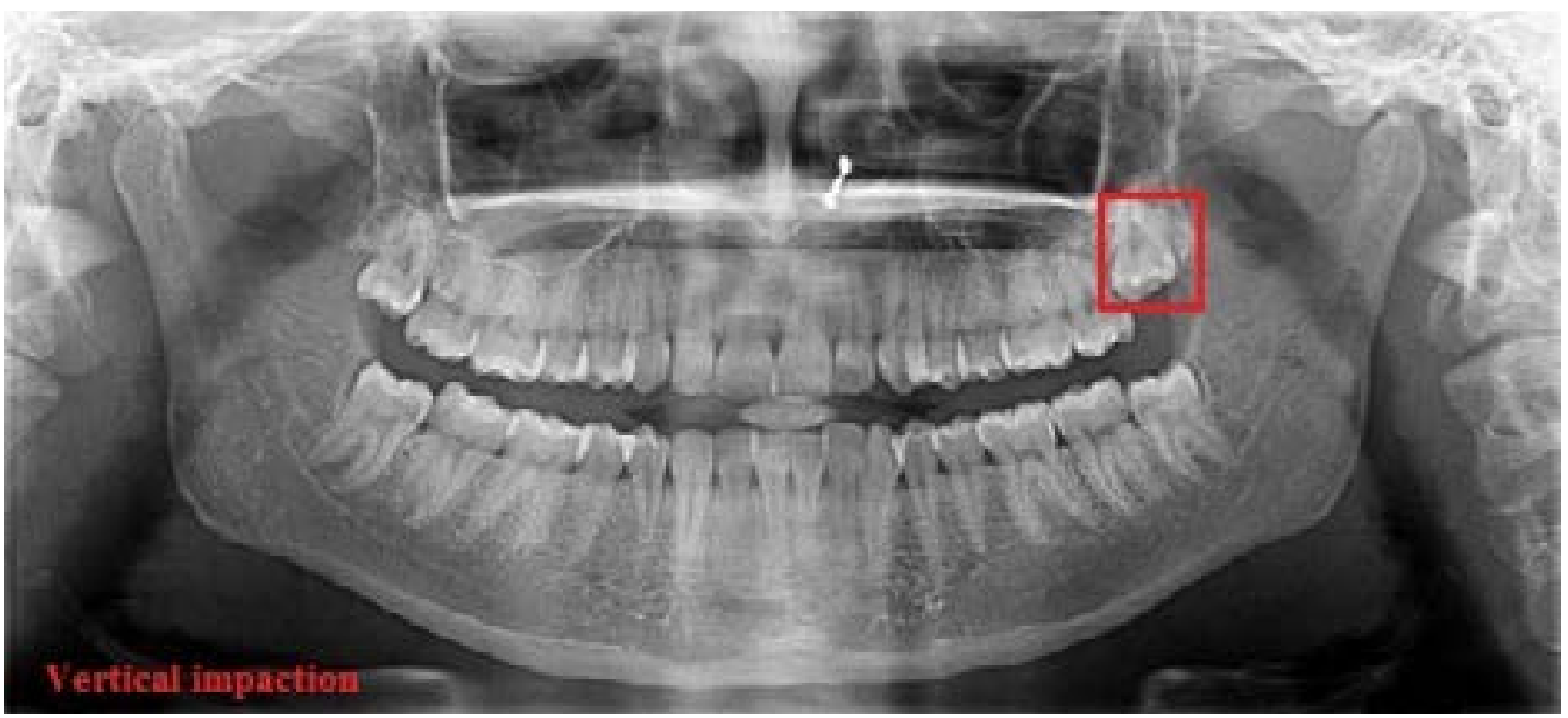

Figure 3. Vertical angulation impaction of the maxillary third molars.

\begin{tabular}{|c|c|c|c|c|}
\hline Authors & Year & Population & Sample Size & $\begin{array}{l}\text { Prevalence of impacted } \\
\text { third molars (\%) }\end{array}$ \\
\hline Sandhu and Kapila' ${ }^{12}$ & 1982 & Indian & 1015 & 26.0 \\
\hline Hattab et al. ${ }^{33}$ & 1995 & Jordanaian & 232 & 33.0 \\
\hline Elsey and Rock ${ }^{10}$ & 2000 & European & - & 73.0 \\
\hline Chu et al. ${ }^{15}$ & 2003 & Hong Kong Chinese & 7486 & 27.8 \\
\hline Quek et al..$^{13}$ & 2003 & Singaporean & 1000 & 68.6 \\
\hline Omar $^{4}$ & 2008 & Hawler & 1150 & 43.8 \\
\hline Ramamurthy et al. ${ }^{1}$ & 2012 & Indian & 1005 & 41.3 \\
\hline Tsabedze $^{8}$ & 2012 & South African & 1215 & 17.0 \\
\hline Hashemipouret al. ${ }^{2}$ & 2013 & Irani & 2300 & 44.3 \\
\hline Sabra and Soliman ${ }^{21}$ & 2013 & Saudi Arabian & 113 & 67.9 \\
\hline Syed et al. ${ }^{5}$ & 2013 & Saudi Arabian & 3800 & 18.7 \\
\hline \multicolumn{3}{|c|}{ Weighted mean } & & 31.3 \\
\hline Present Study & 2014 & South African (Indian) & 222 & 81.0 \\
\hline
\end{tabular}


in young adults, with an estimation that in patients aged between 15-35 years, one in every eleven mandibular third molar teeth are impacted. ${ }^{14} \mathrm{~A}$ number of studies utilized a wider age range and the number of individuals sampled among the different age groups will play a role in the global estimate. $8,15,16$

The prevalence of an impacted third molar tooth was shown in this study to be higher in the mandible than the maxilla, with prevalences of $56.4 \%$ and $43.6 \%$, respectively (Table 4). These results are similar to those of previous studies conducted in Asian countries, viz. India (mandible $=63.21 \%$ and maxilla $=36.79 \%),{ }^{12}$ Hong Kong (mandible $=82.50 \%$ and maxilla=15.60\%), ${ }^{15}$ and Iraq (mandible $=59.04 \%$ and maxilla=39.42\%). ${ }^{4,15}$

A 2008 study considered that the growth of the mandible influences the frequency of impacted mandibular third molar teeth as a small retro-molar space results in an insufficient area for the eruption of the mandibular third molars. ${ }^{17}$ However, other workers found maxillary third molar teeth to be more frequently impacted than mandibular third molar teeth (maxillary impaction:

58.87\%; mandibular impaction: $33.47 \%,{ }^{18}$ and maxillary impaction: 62.57\%; mandibular impaction: $37.44 \%{ }^{19}$ ) (Table 4).

The possibility has been mooted that the discrepancy in the prevalence of the impacted third molars may be due to genetic or racial differences. ${ }^{2}$ Furthermore, the jaw size in relation to the cumulative teeth size has been identified as a contributing factor, which may result from the difference in dietary habits. ${ }^{5}$

\section{Angulation of impacted third molars}

\section{A. Impacted mandibular third molars}

In the present study, the most prevalent pattern of impacted mandibular third molars is mesio-angulation (52.5\%), followed by vertical angulation impaction (24.0\%), with the least prevalent being disto-angulation impaction (1.5\%). The findings of the study, conducted on the South African Indian ethnic group, concurred with the findings of previous investigators all of whom reported mesio-angulation to be the most prevalent in the Indian, Pakistani and Saudi Arabian populations, respectively. ${ }^{5,16,20,21}$ However, the current study differed from other reports which recorded vertical impaction as the most frequent pattern of the mandibular third molar impaction. ${ }^{22-24}$ It is apparent that racial differences may indeed play a role in the angulation pattern of impacted third molars. Furthermore, there are a number of population-specific differences that may exert an influence such as genetically inherited factors, lack of proper dental care and type of food and dietary habits (coarse abrasive diet verses the soft western diet). ${ }^{4}$

Postulated in the literature which has been under review are numerous theories which endeavour to explain the development of impacted mandibular third molars. ${ }^{14}$ The change in orientation of the occlusal surface from a straight mesial direction to a straight vertical direction occurs primarily during root formation and it may be that during this time the tooth rotates from primarily a horizontal, to a mesio-angular and then to a vertical position. ${ }^{25}$

In addition, a study group at Queen's University, known as the Belfast group, proposed that differential root growth between the mesial and distal roots causes the root to either stay mesial or to move to a vertical position, depending on the amount of root development. ${ }^{4}$

\section{Impacted maxillary third molars}

Vertical impaction $(66.7 \%)$ is recorded to be most prevalent in the maxilla, according to Winter's (1926) classification scheme. ${ }^{7}$ This observation concurs with data published in two papers which recorded prevalences of $45.3 \%$ and $52.0 \% 2,5$ respectively. However, two earlier studies reported that disto-angulation was the most frequent type of maxillary third molar impaction, viz. in $75.5 \%$ and $58.5 \%$ of cases respectively. ${ }^{26-28}$ It has been suggested that this discrepancy could be attributed to the maxillary third molars generally assuming different degrees of distal angulation during the primary phases of development. ${ }^{29}$

Since the third molar tooth germ develops from the backward extension of dental lamina, the germs of the third molar tooth develop with their occlusal surfaces positioned distally. This surface then swings into a vertical position only when the maxilla has developed sufficiently to provide room adequate for the movement. ${ }^{30}$ During the period of root development a vertical position is thus essential for normal eruption to occur. However, if the space is insufficient, impaction is likely to occur. ${ }^{29}$

\begin{tabular}{|c|c|c|c|c|c|}
\hline \multirow[t]{2}{*}{ Authors } & \multirow[t]{2}{*}{ Year } & \multirow[t]{2}{*}{ Population } & \multirow[t]{2}{*}{ Sample Size } & \multicolumn{2}{|c|}{$\begin{array}{l}\text { Prevalence of impacted } \\
\text { third molars }(\%)\end{array}$} \\
\hline & & & & Mandible & Maxilla \\
\hline Kramer $^{18}$ & 1970 & American & - & 33.47 & 58.87 \\
\hline Sandhu and Kapila ${ }^{12}$ & 1982 & Indian & 1015 & 63.21 & 36.79 \\
\hline Kruger $^{19}$ & 1984 & - & - & 37.44 & 62.57 \\
\hline Chu et al. ${ }^{15}$ & 2003 & Chinese (Hong Kong) & 7486 & 82.50 & 15.60 \\
\hline Omar ${ }^{4}$ & 2008 & Hawler & 1150 & 59.04 & 39.42 \\
\hline Hashemipour et al. ${ }^{2}$ & 2013 & Iranian & 1215 & 54.90 & 28.80 \\
\hline Syed et al..$^{5}$ & 2013 & Saudi Arabian & 3800 & 49.40 & 18.40 \\
\hline \multicolumn{3}{|c|}{ Weighted mean } & & 68.50 & 20.80 \\
\hline Present Study & 2014 & South African & 222 & 56.40 & 43.60 \\
\hline
\end{tabular}




\section{Level of third molar impaction}

\section{A. Impacted mandibular third molars}

When the Pell and Gregory classification scheme was applied, this study recorded Class B to be the most prevalent type of mandibular third molar impaction, followed by Class $\mathrm{C}$ and, by the least prevalent, Class $\mathrm{A}$, with observations of $54.4 \%$ (B), $29.3 \%$ (C) and $16.3 \%$ (A), respectively. These findings concurred with those of a Singaporean study, which reported Class B to be most prevalent in $85 \%$ of the cases, followed by Class C (9\%) and Class $A(6 \%)$ as the least prevalent. ${ }^{13}$

\section{B. Impacted maxillary third molars}

This study found Class A $(74.8 \%)$ to be the most common type of maxillary third molar impaction, followed by Class $C(15.2 \%)$ with the least prevalent being Class B (10.0\%). These findings confirmed those of a 1988 study. ${ }^{31}$ A more recent investigation reported results similar to the present study, with the highest prevalence being Class A (80.9\%). ${ }^{2}$ However, they recorded Class B (10.9\%) as the second most prevalent, with their investigation showing Class $\mathrm{C}(8.2 \%)$ to be the least frequent type of third molar impaction. ${ }^{2}$

In contrast, the Singapore study reported Class B to be the most common type of maxillary third molar impaction, with a prevalence of $59.0 \%$, followed by Class C (39.0\%) and Class A (3.0\%). ${ }^{13}$ It has been suggested that racial and genetic differences may account for the variation in the level of impaction from one population to another. ${ }^{16}$

\section{Sex estimation}

This study recorded a higher prevalence of impacted third molar teeth in females (54.5\%) which is in agreement with previous studies: $55.7 \%$ females; $44.3 \%$ males; 12 51.0\% females; $49.0 \%$ males; ${ }^{4} 64.9 \%$ females; $35.1 \%$ males. A possible reason is that the jaws of females stop growing as soon as the third molars begin to erupt, whereas in males the growth of the jaws continues beyond the eruption of the third molars. ${ }^{32}$

Therefore, the incidence of third molar impaction is more frequent in females than in males. ${ }^{1,4}$ There is agreement amongst researchers that the mandibular third molar teeth in males erupts approximately three to six months earlier than do these teeth in females, consequently resulting in a higher prevalence of impacted mandibular third molars in females. ${ }^{14,32}$

\section{Age estimation}

The majority of third molar impactions were observed in the age group of 20-25 years (39.2\%), followed by the 16-19 year age interval (33.3\%), with the 26-30 year interval having the least prevalence of impactions (27.5\%).

This correlated with the findings of a study which reported $47.9 \%, 43.3 \%$ and $23.5 \%$ prevalences of impacted third molars in the 21-25, 17-20 and 26-30 year age intervals, respectively. ${ }^{4}$
However, two investigations have recorded the highest prevalence of impacted third molars as being in individuals between 20 - 30 years old, with records of $55.1 \%$ and $57.4 \%$, respectively. ${ }^{15,16}$

This may be due to population-specific differences which vary from one region to another. In addition, these results may be influenced by the number of individuals sampled among the different gender groups.

\section{Limitations}

The study did not include a consideration of crowding in the arches, nor whether the dentition was complete. Both factors may have contributed to the impaction of third molars.

The study did not aim to explore etiological factors. With regards to crowding, the observation made on panorex films would have been limited as to whether or not crowding was present elsewhere in the arch. Further studies which may consider these factors would preferably include study models.

\section{CONCLUSIONS}

The prevalence of impacted third molars in the specific race group studied in the Greater eThekwini Metropolitan population was found to be the higher than the weighted mean recorded in the literature surveyed.

Eighty-one percent of this population presented with at least one impacted third molar, with impactions being more prevalent in females than males (1.2:1). A possible reason for this was that this study analyzed radiographs of patients within a narrow age range (between 16-30 years) as the predominant age of impaction was 18-24 years, ${ }^{33}$ whereas other studies examined samples with a wider age range, and therefore the number of individuals sampled among the different age groups will play a role in the global estimate.

A greater prevalence of impacted third molar teeth was recorded in the mandible than the maxilla, with a ratio of $1.3: 1$, respectively.

In this study, the most prevalent patterns of an impacted third molar were found to be mesio-angulation in the mandible and vertical angulation in the maxilla.

With regard to the level of impaction, Class B and Class A were most common in the mandible and maxilla, respectively. Therefore, to minimise the risk of complications during the removal of third molar, maxillo-facial surgeons, dentists and orthodontists may use these results (classifications) to predict, assess and diagnose the difficulty of surgical procedure and subsequently may be able to evaluate and provide treatment to the patient more efficiently.

In addition, the results may be used to diagnose whether the patient has a predilection for third molar impaction by correlating the type of impaction and the depth of impaction, with age and sex, as the general age of eruption is between 18-24 years. 


\section{References}

1. Ramamurthy A, Pradha J, Jeeve S, Jeddy N, Sunitha J, Kumar S. Prevalence of mandibular third molar impaction and agenesis: A radiographic South Indian Study. Journal of Indian Academy of Oral Medicine and Radiology 2012; 24(3): $173-6$.

2. Hashemipour MA, Tahmasbi-Arashlow M, Fahimi-Hanzae F. Incidence of impacted mandibular and maxillary third molars: A radiographic study in a Southern Iran population. Med Oral Patho Oral Cir Buccal. 2013; 18(1): e140 - 5.

3. Esposito and Caulthard. Impacted wisdom teeth. British Medical Journal 2006; 05: 1-10.

4. Omar LF. Prevalence of impacted wisdom teeth among Hawler young people. MDJ 2008; 5(1): 97-103.

5. Syed KB, Kota Z, Ibrahim M, Bagi MA, Assiri MA Prevalence of impacted molar teeth among Saudi population in Asir Region, Saudi Arabia - A retrospective study of three years. Journal of International Oral Health 2013; 5(1): 43-7.

6. Pretty IA, Sweet D. A look at forensic dentistry - Part 1 : The role of teeth in the determination of human identity. British Dental Journal 2001; 190(7): 359-5.

7. Winter GB. Impacted mandibular third molars. St Louis American Medical Book Company 1926.

8. Tsabedze VN. Prevalence of impacted third molar teeth at Medunsa Oral Health Centre. 2012. Thesis.

9. Pell GT, Gregory BT. Impacted mandibular third molars: Classification and modified techniques for removal. Dental Digest 1933; 39: 330-8.

10. Elsey MJ, Rock WP. Influence of orthodontic treatment on development of third molars. British Journal of Oral Maxillofacial Surgery 2000; 38(4): 350-3.

11. Kramer RM, Williams AC. The incidence of impacted teeth. A survey at Harlem Hospital. Oral Surgery, Ora Medicine and Medical Oral Pathology 1970; 29(2): 237-41.

12. Sandhu SS, Kapila BK. Incidence of impacted third molars. Journal of Indian Dental Assoc 1982; 54: 441-4.

13. Quek SL, Tay CK, Toh SL, Lim KC. Pattern of third molar impaction in a Singapore Chinese population: a retrospective radiographic survey. International Journal of Oral Maxillofacial Surgery 2003; 32: 548-52.

14. Juodzbalys G and Daugela P. Review of literature and a proposal of a classification. Journal of Oral and Maxillofacial Research 2013; 4(2): 1-12.

15. Chu FSC, Li TKH, Lui VKB, Newsome PRH, Chow RLK, Cheung LK. Prevalence of impacted teeth and associated pathologies - a radiographic study of the Hong Chinese population. Hong Kong Medical Journal 2003; 9: 158-63.

16. Khan A, Khitab U, Khan MT. Impacted mandibular third molars: Pattern of presentation and postoperative complication. Pakistan Oral and Dental Journal 2010; 30(2): 307-12.

17. Popescu MA, Popoviou O. The third molar - A dental topic requiring an interdisciplinary approach. Proc, Rom. Acad. Series B, 2008: 175-8

18. Kramer RM, Williams AC. The incidence of impacted teeth A survey at Harlem Hospital. Oral Surgery, Oral Medicine and Medical Oral Pathology 1970; 29(2): 237-41.

19. Kruger GO. Impacted teeth. Textbook of Oral and Maxillofacial Surgery, CV Mosby Co. 1984; 84-98.

20. Biswaris G, Gupta P, Das D. Wisdom teeth - A major problem in the young generation study on the basis of types and associated complications. Journal of College of Medical Science - Nepal 2010; 6(3): 24-8.

21. Sabra SM and Soliman MM. The prevalence of impacted mandibular wisdom with associated physical signs and microbial infections among under-graduate girls at Taif University. KSA. World Applied Science Journal 2014; 21(1): $21-9$.

22. Bataineh AB, Albashairen ZS, Hazza AM. The surgical removal of mandibular third molars: a study in decision making. Quintessence International 2002; 33: 613-7.
23. Sasano T, Kuribard N, likubo M, Yashida A, Saton-Kuiriwa S, Shaji M, Sakamoto M. Influence of an angular position and degree of impaction of third molars on development of symptoms: Long term follow-up under good oral hygiene conditions. Tohoku Journal of Experimental Medicine 2003; 200: 75-83.

24. Almendros-Marques N, Alaejos-Algatrrae,

Qunteros-Bargarello M, Berini-Aytes L, Gay-Escoda C. Factors influencing prophylactic removal of asymptomatic impacted lower third molars. International Journal of Maxillofacial Surgery 2008; 37: 29-35.

25. Miloro M, Ghali GE, Larsen P, Waite P. Peterson's Principles of Oral and Maxillofacial Surgery. People's Medical Publishing House - USA, Shelton, Connecticut. Third Edition (Volume 1). 2012; 97-103.

26. Fonseca JB. Incidencia da inclusao dentaria em 1000 patientes com exame radiografico complete. Sel Odont 1956; 11(2): 1-8.

27. Leite MC. Estudo radiografico da incidencia de terceiros molare incluses. Rev Odont Alferas 1986; 87(9): 57-62.

28. Clovis M, Eliston C, Filho T, Lopes J. Third molars: classification and prevalence in the cities of Cunha Pora, Maravilna and Palmitos in the Northwest of Santa Catarina State in Brazil. FAC. Odonto/PUCRS 2006; 21(51): $55-66$.

29. Artun J, Behbehani F, Thalib L. Prediction of maxillary third molar impaction in adolescent orthodontic patients. Angle Orthodontist, 2005; 75(6): 904-11.

30. 30. Ragini, Singh N, Goyal S, Padmanabhan P, Munjal P. Prediction of third molar eruption. Journal of Indian Orthod Soc 2003; 36: 103-12.

31. Hugoson A, Kugelberg CF. The prevalence of third molars in a Swedish population. An epidemiological study. Community Dental Health 1988; 5:121-38.

32. Hellman M. Some aspects of wisdom teeth and their impaction. Journal of Clinical and Oral Pathology 1988; 26-45.

33. Hattab FN, Rawashedeh MA, Fahmy MS. Impacted status of third molars in Jordanian students. Oral Surgery, Oral Medicine, Oral Pathology, Oral Radiology and Endodontics 1995; 79: $24-9$. 